Short Report

\title{
Antagonism between Manganese and Caffeine on the SA Node of the Dog Heart in Situ
}

\author{
Shigetoshi Chiba and Koroku Hashimoto \\ Department of Pharmacology, Tohoku University School of \\ Medicine, Sendai
}

Chiba, S. and Hashimoto, K. Antagonism between Manganese and Caffeine on the SA Node of the Dog Heart in Situ. Tohoku J. exp. Med., 1973, 109 (1). 95-96 - Direct perfusion of the sinus node artery under a constant pressure of $100 \mathrm{~mm} \mathrm{Hg}$ was arranged in eight canine hearts in situ. The administration of $\mathrm{MnCl}_{2}$ at doses from $10 \mu \mathrm{g}$ to $10 \mathrm{mg}$ into the sinus node artery induced a longlasting negative chronotropic response. $\mathrm{MnCl}_{2}$ blocked the effects of caffeine which induced double peaked positive chronotropic responses, i.e., initial rapid acceleration of sinus rate followed by slow and long-lasting acceleration. The initial acceleration was resistant to propranolol or tetrodotoxin, but completely blocked by $\mathrm{MnCl}_{2}$. Thus, the initial positive chronotropic response to caffeine may be probably ascribed to its essential effect of the movement of $\mathrm{Ca}$ ions on the SA nodal pacemaker cell. $\mathrm{SA}$ node; $\mathrm{MnCl}_{2}$; caffeine; norepinephrine

Since it has been reported that the increase of Ca conductance was suppressed by $\mathrm{Ma}$ ion (Hagiwara and Nakajima 1966), Lu and Brooks (1969) observed that both the diastolic depolarization and the action potential of a true pacemaker cell to various degrees according to the concentration used. In this study, we investigated the antagonism between manganese and caffeine on the SA node of the dog heart in situ.

The constant pressure perfusion of the sinus node artery (Hashimoto et al. 1967) was performed in eight vagotomized dogs anesthetized with sodium pentobarbital, $30 \mathrm{mg} / \mathrm{kg}$ i.v. The selective administration of $\mathrm{MnCl}_{2}$ at doses from $10 \mu \mathrm{g}$ to $10 \mathrm{mg}$ caused a longlasting negative chronotropic effect which was not influenced by i.a. pretreatment with atropine, 10 to $30 \mu \mathrm{g}$. The threshold dose for induction of sinus deceleration by $\mathrm{MnCl}_{2}$ was about $10 \mu \mathrm{g}$. At a dose level of 3 to $10 \mathrm{mg}$, sinus block was frequently observed. After injection of 1 to $3 \mathrm{mg}$ of $\mathrm{MnCl}_{2}$ into the sinus node artery, the positive chronotropic effects of norepinephrine, 0.03 to $0.3 \mu \mathrm{g}$, and caffeine, $100 \mu \mathrm{g}$ to $1 \mathrm{mg}$, were markedly inhibited as shown in Figure 1. In previous papers (Chiba et al. 1972a, b), we reported

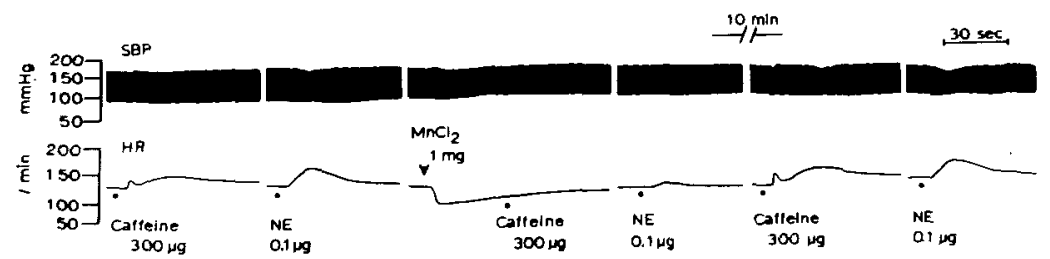

Fig. 1. Blocking effect of $1 \mathrm{mg}$ of $\mathrm{MnCl}_{2}$ on the positive chronotropic responses to either $300 \mu \mathrm{g}$ of caffeine or $0.1 \mu \mathrm{g}$ of norepinephrine. SBP, systemic blood pressure. HR, heart rate. NE, norepinephrine.

Received for pubjication, June $23,1972$. 
that caffeine induced a double peaked positive chronotropic response when administered into the canine sinus node artery, i.e., an initial rapid acceleration followed by a longlasting acceleration response of sinus node, and that an initial acceleration response was resistant not only to propranolol but also to tetrodotoxin while the acceleration in the later phase was completely blocked by either of them. Thus, it was concluded that a secondary long-lasting response to caffeine is due to catecholamine release from the sympathetic nerve terminals.

In this study, we demonstrated that manganese chloride suppressed not only the intrinsic sinus node activity but also the essential caffeine effect on it. This suggests that an initial positive chronotropic response to caffeine is due to acceleration of the calcium dependent pacemaker potential.

\section{References}

1) Chiba, S., Hashimoto, K. \& Hashimoto, K. (1972a) Pharmacological analysis of chronotropic responses of the S-A node to caffeine. Europ. J. Pharmacol., 18, 116120.

2) Chiba, S., Kubota, K. \& Hashimoto, K. (1972b) Double peaked positive chronotropic response of the isolated blood-perfused S-A node to caffeine. Tohoku J. exp. Med., 107, 101-102.

3) Hagiwara, S. \& Nakajima, S. (1966) Differences in $\mathrm{Na}$ and $\mathrm{Ca}$ spikes as examined by application of tetrodotoxin, procaine, and manganese ions. J. gen. Physiol., 49, 793-806.

4) Hashimoto, K., Tanaka, S., Hirata, M. \& Chiba, S. (1967) Responses of the sinoatrial node to change in pressure in the sinus node artery, Circulat. Res., 21, 297304.

5) Lu, H.H. \& Brooks, McC. C. (1969) Role of calcium in cardiac pacemaker cell action. Bull. N.Y. Acad. Med, 45, 100. 